\title{
Informe de los encuentros sobre la didáctica de lenguas en la Universidad de Rouen: buenas expectativas en el interés por el plurilingüismo
}

Ana-Isabel Ribera Ruiz de Vergara

\section{(2) OpenEdition}

\section{Journals}

Edición electrónica

URL: https://journals.openedition.org/esp/2762

DOI: $10.4000 /$ esp.2762

ISSN: 2532-0319

\section{Editor}

Centre d'Information sur l'Éducation Bilingue et Plurilingue

\section{Edición impresa}

Fecha de publicación: 1 diciembre 2013

Paginación: 57-62

ISSN: 1127-266X

\section{Referencia electrónica}

Ana-Isabel Ribera Ruiz de Vergara, «Informe de los encuentros sobre la didáctica de lenguas en la Universidad de Rouen: buenas expectativas en el interés por el plurilingüismo», Éducation et sociétés plurilingues [En línea], 35 | 2013, Puesto en línea el 01 febrero 2020, consultado el 29 agosto 2021. URL: http://journals.openedition.org/esp/2762 ; DOI: https://doi.org/10.4000/esp.2762 


\section{INFORME DE LOS ENCUENTROS SOBRE LA DIDÁCTICA DE LENGUAS EN LA UNIVERSIDAD DE ROUEN: BUENAS EXPECTATIVAS EN EL INTERÉS POR EL PLURILINGÜISMO}

\section{Ana-Isabel RibERA RuIZ DE VERGARA}

En avril 2011 j'ai organisé la première Rencontre sur la Didactique des Langues à l'Université de Rouen, avec pour principal objectif d'expliquer à mes étudiants d'Études Romanes (spécialité espagnol) et de LEA (Langues Étrangères Appliquées), comment et pourquoi on choisit et on crée des activités de communication langagière qui leur sont proposées dans les cours de compréhension et expression écrites, compréhension et expression orales et phonétique. Dans un second temps, mon intention était d'attirer les professeurs, formateurs de professeurs, doctorants, chercheurs et autres personnes intéressées par la didactique des langues, pour, avec le temps, se regrouper pour créer et avancer des projets communs de recherche sur la linguistique appliquée à la didactique des langues en contexte universitaire. Trois ans plus tard, trois rencontres ont eu lieu et le projet prend forme. Voici le compte-rendu de ces trois années de rencontres.

In April 2011 I organized the First Encounter on Language Didactics at Rouen University. The main objective was to explain to my students how and why one chooses to study language activity through witten comprehension, oral expression and phonetics. I then wished to attract teachers, trainers, PhD students and other people interested in language didactics, to propose joint research projects in applied linguistics in University language teaching. Three years later, three encounters have taken place and the project is on-going. Here is the record of those encounters.

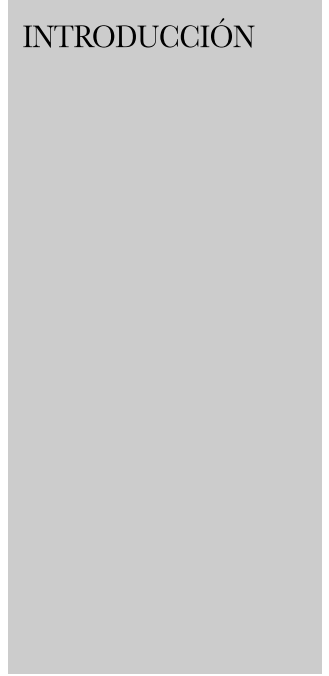

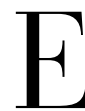
n el departamento de Filología Románica de la Universidad de Rouen, en colaboración con el laboratorio ERIAC (Équipe de Recherche Interdisciplinaire sur les Aires Culturelles), hemos llevado a cabo tres seminarios titulados Encuentros sobre la Didáctica de las Lenguas. El primer seminario tuvo lugar en abril de 2011 y, desde entonces hasta hoy, ya hemos realizado tres seminarios:

- Primer encuentro sobre la Didáctica de las Lenguas (abril 2011): La competencia comunicativa en primer año de español en la universidad.

- Segundo encuentro sobre la Didáctica de las Lenguas (abril 2012): El teatro como herramienta para el aprendizaje de las lenguas.

- Tercer encuentro sobre la Didáctica de las Lenguas (abril 2013): La pédagogie numérique des langues.

El tipo de público asistente a estos seminarios está compuesto, en general, por una parte, por profesores, formadores de profesores, doctorandos, investigadores y estudiantes interesados por la didáctica de lenguas; por otra parte, el público está constituido tanto por los estudiantes que asisten a nuestras clases de lengua extranjera para especialistas como por los que asisten a nuestras clases de lengua extranjera 
Informe de los encuentros sobre la didáctica de lenguas en la Universidad de Rouen

A.-I. Ribera Ruiz de Vergara

OBJETIVOS Y

DESARROLLO DE LOS SEMINARIOS

SOBRE LA

DIDÁCTICA DE LAS

LENGUAS

PRIMER

ENGUENTRO

(ABRIL 2011):

LA COMPETENCIA

COMUNICATIVA EN

PRIMER AÑNO DE

ESPAÑOL EN LA

UNIVERSIDAD. para fines específicos.

El objetivo principal de los seminarios sobre la Didáctica de las Lenguas, llevados a cabo cada mes de abril en la Universidad de Rouen, es el de explicar cómo y por qué se escogen y/o se crean las actividades de comunicación lingüística, concernientes a la enseñanza/aprendizaje de la lengua extranjera, que se les propone a nuestros estudiantes en los primeros semestres de las Facultades de Filología Románica y de LEA (Lenguas Extranjeras Aplicadas), con el fin de debatir y avanzar en el análisis de la didáctica de lenguas en los dos primeros años del ciclo universitario.

Este primer encuentro se realizó en francés y en español y se llevó a cabo en tres partes:

1) En la primera parte se les presentó a los asistentes el tema principal y los objetivos del encuentro. El tema principal se refería a la enseñanza/aprendizaje de la lengua extranjera (en este caso el español) en primer año de Filología Románica. El objetivo del seminario era explicarle al público asistente cómo y por qué se escogen y/o se crean las actividades de comunicación lingǘstica que se les propone a nuestros estudiantes de primer año de Filología Románica.

Antes de pasar a la segunda parte del seminario, se presentó el prototipo de estudiante de primer año de Filología Románica. Según unas encuestas llevadas a cabo en la Universidad de Rouen con los estudiantes que realizan el primer año de Filología Románica, estos piensan, en un 70\%, tener un nivel de lengua española bastante elevado y, darse cuenta, desde las primeras semanas de estudio en la universidad, que el nivel con el que acceden a la universidad no es tan elevado como ellos pensaban. Algo más de la mitad de los encuestados, un $60 \%$ aproximadamente, dicen acceder a la universidad con el fin de convertirse en profesores de español. Entre las profesiones deseadas por el $40 \%$ restante, las más destacadas son la traducción, el turismo, las profesiones relacionadas con la comunicación y el periodismo. Entre las asignaturas con las que dicen llegar a alcanzar el objetivo propuesto, en lo que a nivel de lengua se refiere, más de la mitad de los encuestados opina que es la gramática la asignatura que necesitan estudiar en profundidad.

2) En la segunda parte se explicó, por un lado, que la competencia comunicativa está constituida por unas destrezas relacionadas con los componentes lingüístico, sociolingüístico-cultural y pragmático. Estas destrezas se desarrollan a través de asignaturas tales como la comprensión escrita $(\mathrm{CE})$, la expresión o producción escrita $(\mathrm{EE})$, la comprensión oral $(\mathrm{CO})$, la expresión o producción oral $(\mathrm{EO})$, la interacción oral y la fonética.

Por otro lado, se les indicó a los asistentes cuáles son los elementos teóricos y prácticos que hay que tener en cuenta en la enseñanza/aprendizaje de la com- 
Informe de los encuentros sobre la didáctica de lenguas en la Universidad de Rouen

A.-I. Ribera Ruiz de Vergara petencia comunicativa. En primer año de Filología Románica de la Universidad de Rouen, nuestro objetivo es el de guiar y dirigir al aprendiente para que se acerque, al máximo, al nivel B2 en la competencia comunicativa de la lengua. A continuación, mostramos, de manera esquematizada, las exigencias referidas al nivel $\mathrm{B} 2$ :

Objetivos para $1^{\mathrm{er}}$ año Filología Románica (especialidad español) Siguiendo el Marco Común Europeo de Referencia para las Lenguas (MCERL)

Acercarse al Nivel B2 (nivel avanzado e independiente) = Adquirir la competencia comunicativa al nivel B2

¿CÓMO?

Acercando a los alumnos hacia la autonomía en la utilización de la lengua a través de las asignaturas de $\mathrm{CE}, \mathrm{EE}, \mathrm{CO}, \mathrm{EO}$, interacción, fonética

Se les mostró cómo, para lograr este objetivo, los profesores guían al aprendiente en el aprendizaje de la competencia comunicativa, y cómo, a partir de las asignaturas anteriormente citadas, se practican los diferentes componentes de la competencia comunicativa.

Por ejemplo, con la comprensión y expresión escritas se ponen en práctica, de forma más destacada, el componente lingüístico (en la producción escrita, saber utilizar correctamente la conjugación, el léxico, la sintaxis, la ortografía, la puntuación, la acentuación y, en cierta medida, la fonología) y el componente pragmático (saber reconocer el tipo de texto, diferenciar las ideas principales de las secundarias, saber organizar y estructurar las ideas).

Con la comprensión y expresión orales se ponen en práctica el componente lingǘstico (hacer uso correcto en la producción oral de la conjugación, el léxico, la sintaxis, la prosodia, la fonética y la fonología); el componente sociolingǘstico y cultural (en este componente, entran en juego los rasgos relativos al uso de la lengua y, además, al aprendiente se le exige utilizar correctamente los marcadores propios de las relaciones sociales, las reglas de cortesía, las expresiones populares, distinguir los acentos) y el componente pragmático (saber organizar, adaptar y estructurar el discurso).

Con la interacción oral se practican los mismos componentes que intervienen en la comprensión y expresión orales.

Con la fonética se aprenden y practican las destrezas básicas necesarias para el buen aprendizaje de la comprensión y expresión orales. Se explicó que las actividades propuestas en fonética se realizan después de haber analizado los rasgos fónicos de las lenguas francesa y española, para ver cuáles son los rasgos diferenciadores entre ambas lenguas, y, por consiguiente, los rasgos inexistentes en francés con respecto al español. De esta manera, se logra agrupar los soni- 
Informe de los encuentros sobre la didáctica de lenguas en la Universidad de Rouen

A.-I. Ribera Ruiz de Vergara

\section{SEGUNDO}

ENGUENTRO SOBRE LA DIDÁCTICA DE LAS LENGUAS (ABRIL 2012): EL TEATRO COMO HERRAMIENTA PARA ELAPRENDIZAJE DE LAS LENGUAS. dos que van a causar mayor dificultad a los aprendientes francófonos.

3) En la tercera parte, se les mostró, a los asistentes al encuentro, algunas actividades de comprensión y expresión escritas, comprensión y expresión orales, interacción oral y fonética, todas ellas llevadas a cabo con nuestros estudiantes de primer año de Filología Románica de la Universidad de Rouen.

El Primer encuentro sobre la Didáctica de las Lenguas concluyó con la invitación a participar en el Segundo encuentro sobre la Didáctica de las Lenguas que tendría lugar al año siguiente.

Este segundo encuentro se realizó en español y en italiano y se llevó a cabo en tres partes:

1) En la primera parte se les presentó a los asistentes el tema principal y los objetivos del encuentro. El tema principal se refería a la enseñanza/aprendizaje de la lengua extranjera (en este caso el español y el italiano) en primer año de Filología Románica en la Universidad de Rouen y en la enseñanza/aprendizaje de lenguas en el LANSAD (Langues pour Spécialistes d'Autres Disciplines) en la Universidad de Grenoble. El objetivo del seminario era explicarles a los asistentes al encuentro cómo y por qué se escogen y/o se crean, a partir de actividades relacionadas con el teatro, las actividades de comunicación lingǘstica que se les propone a los estudiantes de primer año de Filología Románica en la Univ. de Rouen y de LANSAD en la Univ. de Grenoble.

2) En la segunda parte, después de explicarle a la asistencia algunos de los fundamentos científicos en los que se basa la idea de que el teatro puede ser una herramienta útil para la enseñanza/aprendizaje de lenguas, los dos ponentes (Filippo Fonio, profesor e investigador en lingüística aplicada en el LANSAD en la Universidad de Grenoble y Ana Isabel Ribera, profesora e investigadora en lingǘstica aplicada en la Universidad de Rouen) destacaron tres niveles que aporta el teatro para la adquisición lingüística de lenguas:

- El primer nivel. La fonética y la competencia ortoépica: Se le transmite al aprendiente no sólo la pronunciación normativa sino también diversas variaciones de la pronunciación de una lengua.

- El segundo nivel. La fonética sintáxica: Se le sensibiliza al aprendiente con la musicalidad de una lengua y con el encadenamiento harmonioso de las secuencias habladas.

- El tercer nivel. La prosodia: Se le transmite al aprendiente la entonación de la lengua.

Aparte de estos tres niveles lingüísticos, relacionados con la competencia lingüística de la lengua, se mencionaron, asimismo, algunas dimensiones, que aporta el teatro, correspondientes a la competencia sociolingüística y cultural en la enseñanza/aprendizaje de lenguas, tales como:

Los diferentes registros de la lengua, las relaciones verticales y horizontales en la comunicación, las relaciones entre los sexos, el tuteo, las reglas de cortesía, etc.

3) En la tercera parte, los dos ponentes mostraron a los asistentes al encuentro, 
Informe de los encuentros sobre la didáctica de lenguas en la Universidad de Rouen

A.-I. Ribera Ruiz de Vergara

\section{TERCER}

ENCUENTRO SOBRE LA DIDÁCTICA DE LAS LENGUAS (ABRIL 2013): LA PÉDAGOGIE NUMÉRIQUE DES LANGUES. algunas actividades teatrales llevadas a cabo con estudiantes de primer año de Filología Románica de la Universidad de Rouen y de LANSAD en la Universidad de Grenoble.

El Segundo encuentro sobre la Didáctica de las Lenguas concluyó con la invitación a participar en el Tercer encuentro sobre la Didáctica de las Lenguas que tendría lugar al año siguiente.

Este tercer encuentro se realizó en francés y en español y se llevó a cabo en tres partes:

1) En la primera parte se les presentó a los asistentes el tema principal y los objetivos del encuentro. El tema principal se refería a la enseñanza/aprendizaje de la lengua extranjera (en este caso el alemán, el español, el francés y el inglés) en Filología Alemana, Filología Románica, FLE (Francés Lengua Extranjera), Filología Inglesa y LEA (Lenguas Extranjeras Aplicadas). El objetivo del seminario era explicarles a los participantes cómo y por qué, utilizando las nuevas tecnologías, se escogen y/o se crean las actividades de comunicación lingüística que se les propone, en Filología y LEA, a nuestros estudiantes de Rouen.

2) En la segunda parte, se les presentó a los asistentes al ponente invitado: Patrick Lemaire, experto en ingeniería pedagógica en la Universidad de Rouen, que analizó las herramientas numéricas de las que se dispone en la pedagogía numérica para la enseñanza/aprendizaje de lenguas.

En este encuentro intervinieron asimismo:

- Representando la enseñanza/aprendizaje de la lengua inglesa, Philippe Decloître, experto en ingeniería pedagógica y docente de inglés, que propuso algunos dispositivos numéricos para la enseñanza/aprendizaje a distancia;

- Representando la enseñanza/aprendizaje de la lengua alemana, Bertrand Blanchard, encargado de la misión CLES (Certificación de Competencias en Lenguas de la Enseñanza Superior) en la Universidad de Rouen y docente de alemán, que habló sobre el aprendizaje de lenguas, en particular el alemán, a partir del CLES;

- Representando la enseñanza/aprendizaje del español, Esther Ceballos, docente de español, y Ana-Isabel Ribera, profesora titular e investigadora en lingǘstica aplicada en la Universidad de Rouen, explicaron cómo utilizar las nuevas tecnologías, las plataformas numéricas y las redes sociales como apoyo a la clase presencial, en la enseñanza/aprendizaje del español;

- Representando la enseñanza/aprendizaje de FLE, Marion Dufour, doctora en ciencias del lenguaje, presentó la plataforma del proyecto PFC [Fonología del Francés Contemporáneo, (ver sitografia al final del artículo)] como recurso innovador en la enseñanza/aprendizaje de FLE.

3) En la tercera parte, algunos de los ponentes mostraron a los asistentes 
Informe de los encuentros sobre la didáctica de lenguas en la Universidad de Rouen

A.-I. Ribera Ruiz de Vergara

CONGLUSIÓN Y EXPECTATIVAS

SITOGRAFÍA al encuentro, algunas actividades prácticas sobre comunicación lingüística, creadas con la ayuda de las nuevas tecnologías, dirigidas a estudiantes de lengua extranjera.

El Tercer encuentro sobre la Didáctica de las Lenguas concluyó con la invitación a participar en el Cuarto encuentro sobre la Didáctica de las Lenguas al año siguiente.

$\mathrm{Al}$ principio de este artículo, se han comentado los dos objetivos principales con los que se han organizado los seminarios sobre didáctica de lenguas, denominados Encuentros sobre la Didáctica de las Lenguas. El primer objetivo se va logrando cada año, desde 2011, y, además, las expectativas son positivas puesto que los seminarios ya no sólo reúnen a los estudiantes de Filología Románica y LEA, sino que cada año se van abriendo a estudiantes de Filología Alemana, Inglesa, FLE y estudiantes de lengua extranjera para fines específicos. El segundo objetivo muestra también unas expectativas positivas puesto que los seminarios acogen ya no sólo a ponentes especializados en la didáctica de lenguas románicas, sino también a ponentes especialistas en la didáctica de otras lenguas. Para acabar, me gustaría resaltar que, en un principio, los seminarios se celebraban con la colaboración y el apoyo del laboratorio de investigación ERIAC (mencionado en la introducción de este artículo); a partir del 2014, a la colaboración del ERIAC se le irán sumando las colaboraciones del REDESC (Recherches en Didactique et Sociolinguistique sur l'Espagnol et le Catalan) y el GERES (Groupe d'Étude et de Recherche en Espagnol de Spécialité). Queda reflejado, en todo caso, el interés por el plurilingüismo.

Para información sobre el Marco Común Europeo de Referencia para la Lenguas (MCER), consultar el sitio http://cvc.cervantes.es/ensenanza/biblioteca_ele/marco/

Para información sobre el Cadre Européen Commun de Référence pour les Langues (CECRL), consultar el sitio

http://www.coe.int/T/DG4/Linguistic/Source/Framework_FR.pdf Para información sobre la certificación de Competencias en Lenguas de la Enseñanza Superior (CLES), consultar el sitio http://www.certification-cles.fr/

Para información sobre el proyecto de Fonología del Francés Contemporáneo (Phonologie du Français Contemporain, PFG), consultar el sitio http://www.projet-pfc.net/

Para información sobre los seminarios Rencontres sur la Didactique des Langues en la Universidad de Rouen, consultar los sitios http://eriac.net/didactique-des-langues/; http://eriac.net/troisiemerencontre-sur-la-didactique-des-langues/ 